\title{
Minimizing the Impact of Large Freight Vehicles in the City: A Multicriteria Vision for Route Planning and Type of Vehicles
}

\author{
Sara Ezquerro $\mathbb{D}$, Juan P. Romero, Jose L. Moura, Juan Benavente, and Ángel Ibeas $\mathbb{D}$ \\ G.I.S.T. Group of Research in Transport Systems, University of Cantabria, Cantabria, Spain \\ Correspondence should be addressed to Sara Ezquerro; sara.ezquerro@unican.es
}

Received 25 August 2017; Revised 9 January 2018; Accepted 10 January 2018; Published 11 February 2018

Academic Editor: Edward Chung

Copyright (C) 2018 Sara Ezquerro et al. This is an open access article distributed under the Creative Commons Attribution License, which permits unrestricted use, distribution, and reproduction in any medium, provided the original work is properly cited.

\begin{abstract}
The impact of freight transport in cities is significant, and as such correct planning and management thereof help reduce their enormous negative impact. Above all, the special large vehicles have a greater impact than the remainder of freight vehicles, so a special attention should be paid to them. The vehicles which supply or pick up large amounts of goods at specific points throughout the city are an example of this type of vehicles. The aim of this paper is to minimize the cost of this freight transport type from a social, economic, and environmental viewpoint. To this effect, an optimization model has been proposed based on bilevel mathematical programming which minimizes the total system costs. City network model data are obtained on the lower level such as vehicle flow and travelling times, which are then used on the upper level to calculate total system costs. The model has been applied to a real case in Santander (Spain), whose final result shows the size and typology of the fleet of vehicles necessary to have the least impact on the city. The greater the vehicles size is (i.e., using fewer trucks), the less the cost of the freight transport is.
\end{abstract}

\section{Introduction}

Freight transport in the urban environment has a great impact on the city, that is, increase in congestion, pollution, costs, and so on. Many researchers have studied the impact of different policies in freight transport [1-3]. In some cases, access to the city centre is restricted to reduce social, environmental, and economic impacts [4].

Different criteria can be used to choose which typology of vehicles can or cannot enter the city centre, such as weight limits in Santander [5] or vehicle emissions in the case of Rome [6]. However, there are exceptional situations where this kind of vehicle is allowed to drive through the city centre due to specific circumstances (e.g., material delivery and pick-up on a construction site). This is why in those situations where the presence of freight transport increases at a specific point albeit due to increase in vehicle frequency and/or typology, consideration should be given to the reduction of its impact on the city. This paper studies the impact of the presence of these vehicles, less common in city centres.

This paper builds upon prior research by the authors on freight transport simulation and optimization models. The aim is go one step further and take a closer approach to the reality extant in cities; hence, unlike in prior studies [7], this one researched the impact of an increase in freight transport during a specific period of time, taking into account variable vehicle capacity and fleet.

This problem can be resolved via application of the supply chain problem when materials need delivering to a certain point following a specific schedule. Numerous researchers have also modelled and simulated the supply chain [8]. Reiner and Trcka [9] modelled and designed the supply chain structure for a food company. Guo et al. [10] carried out a study where they had to minimize the system costs (construction, operation, information processing, and transport costs and likewise coal tax) for a route-planner model for fresh food e-commerce companies. Others, however, have undertaken more innovative studies, such as Smart supply chains [11] or how Smart Cities affect the supply chain [12].

Furthermore, a bilevel methodology has been applied to minimize the impact of large freight vehicles. Bilevel optimization is a kind of optimization that allows one problem to be nested within another, so it can explicitly represent the mutual action between the upper level and lower level. In addition, it allows solving two decision levels. For example, in the upper level, the freight systems planner makes the 
decisions, and, in the lower level, the private transport users make decisions based on the decisions of the first level. In essence, the bilevel model allows considering how heavy truck traffic affects traffic throughout the city. Moreover, bilevel programming can be used to analyse two different objectives and can reflect some practical problems better [13]. Bilevel optimization methodology has been used by many transport researchers to study different subjects, such us public transport optimization (e.g., best bus stops locations [14], the relationship between transport and residence [15]), or it has been used in freight transport optimization for planning the delivery of supplies to large public infrastructure works [16]. In this study, as in Romero et al. [7], the bilevel optimization takes into account in the upper level environmental, economic, and social costs, while there are other studies where only the economic cost has been considered [17].

Freight vehicles are the land transport vehicles with the greatest impact on pollution in cities; nevertheless, the movement of all vehicles must be considered regarding environmental contamination in the urban area. Transport significantly contributes to the major pollutant emissions (NOX, NMVOC, CH4, PM, and CO2), which is why they have been considered when studying the environmental impact of transport, as Romero et al. [7] did. It is worth highlighting that pollutant emissions from all transport sectors have dropped considerably since 1990, despite the general increase in vehicle movement [18]. Adams et al. [19] described existing initiatives which endeavoured to improve the quality of data explaining air quality and pollutant emissions; air quality monitoring is an example [20]. However, knowing the vehicle emission models is important when planning transport routes if we wish to reduce pollutant emissions [21]. Wang et al. [22] researched gas dispersion characteristics and particles due to traffic in Hong Kong, considering CO and PM 2.5.

Freight transport optimization models can be studied considering one or multiple viewpoints. Behrends et al. [23] explain that sustainable urban freight transport (SUFT) must take into account three points of view: social, economic, and environmental. For that reason, these three points have been considered in this paper, as well as in Romero et al. [7]. But, in other studies, one or two of these points have been applied. Yan et al. [24] designed a model whose sole aim was to minimize operation costs, excluding social and environmental costs. Nevertheless, many other studies also did consider social and environmental costs. He et al. [25] built a multipurpose model on logistics network planning to minimize total logistics network costs and likewise total carbon emissions. Browne et al. [2] reviewed the initiatives implemented by local authorities to reduce the environmental and social impact of urban freight transport in cities in 4 countries (UK, Japan, the Netherlands, and France).

To summarise, this paper studies the impact of the increase of large freight vehicles movement during a certain period of time within a city when they have a specific goods' delivery/pick-up point. The study has been carried out from an economic (operation costs), social (congestion), and environmental (emission of pollutants) point of view.
This problem has been studied by other researchers. Moura et al. [16] proposes an optimization-simulation model for planning the transport of supplies to large public infrastructure works located in congested urban areas. But, the difference lies in that the methodology developed in this paper considers different types of the fleet-in size and typology - to minimize the total cost of the system, and nevertheless Moura et al. do not consider it

The introduction and State of the Art have been presented in this section, and the rest of the paper is arranged as follows: Section 2 describes the methodology used, then Section 3 applies the proposed methodology in a city along with presentation of main results, and, finally, Section 4 sets out the main conclusions.

\section{Methodology}

This paper presents a model to optimize large freight vehicle management and planning in city centres (lorries) used to load and unload large quantities of goods. The model considers a number of potential routes, which are defined by the restrictions of space and turning radii required by vehicles of this kind.

The purpose of the model is to determine journey distribution via different routes by defining fleet capacity and size, to minimize economic, social, and environmental costs. The lorries interact with the other transport means travelling in the city, like cars, buses, and smaller freight vehicles (vans or light trucks) and should be considered in the network modelling and calibration to which the optimization model will be applied. The optimization model considers total cost of the system, that is, social costs comprising bus and car user costs, bus operation and freight vehicle costs, and likewise environmental costs of all vehicles.

The optimization model is based on application of a bilevel mathematical program (Figure 1) [7, 16, 29] to find the best alternatives from an economic, social, and environmental viewpoint. From the lower level, via the city network model, vehicle flow, access, waiting and travelling times, and so on are obtained and then used on the upper level. At the upper level, an exhaustive search optimization is used to evaluate all the possibilities, to afterwards obtain those solutions that minimize total system cost:

$$
\begin{aligned}
& \operatorname{Min}(\text { System costs }) \\
& \text { System Cost }=\mathrm{Cu}+\mathrm{Cop}+\mathrm{Cma} \\
& \mathrm{Cu}=\mathrm{Cu}_{\mathrm{C}}+\mathrm{Cu}_{\mathrm{B}} \\
& \mathrm{Cu}_{\mathrm{C}}=\varphi_{\text {Travel, } \mathrm{C}} \cdot T_{\text {Travel, } \mathrm{C}} \\
& \mathrm{Cu}_{\mathrm{B}}=\varphi_{\text {Acc, } \mathrm{B}} \cdot T_{\text {Acc }, \mathrm{B}}+\varphi_{\mathrm{Egr}, \mathrm{B}} \cdot T_{\mathrm{Egr}, \mathrm{B}}+\varphi_{\text {Wai, } \mathrm{B}} \cdot T_{\text {Wai, } \mathrm{B}} \\
& \quad+\varphi_{\text {Travel, } \mathrm{B}} \cdot T_{\text {Travel, } \mathrm{B}}+\varphi_{\text {Tra, } \mathrm{B}} \cdot T_{\text {Tra }, \mathrm{B}},
\end{aligned}
$$

where $\mathrm{Cu}$ is total users cost; $\mathrm{Cu}_{\mathrm{C}}$ is car users cost; $\mathrm{Cu}_{\mathrm{B}}$ is bus users cost; $T_{\text {Travel,C }}$ is car travel time; $\varphi_{\text {Travel,C }}$ is Car travel time worth; $T_{\mathrm{Acc}, \mathrm{B}}$ is bus access time; $\varphi_{\mathrm{Acc}, \mathrm{B}}$ is bus access time worth; $T_{\mathrm{Egr}, \mathrm{B}}$ is bus egress time; $\varphi_{\mathrm{Egr}, \mathrm{B}}$ is bus egress time worth; 


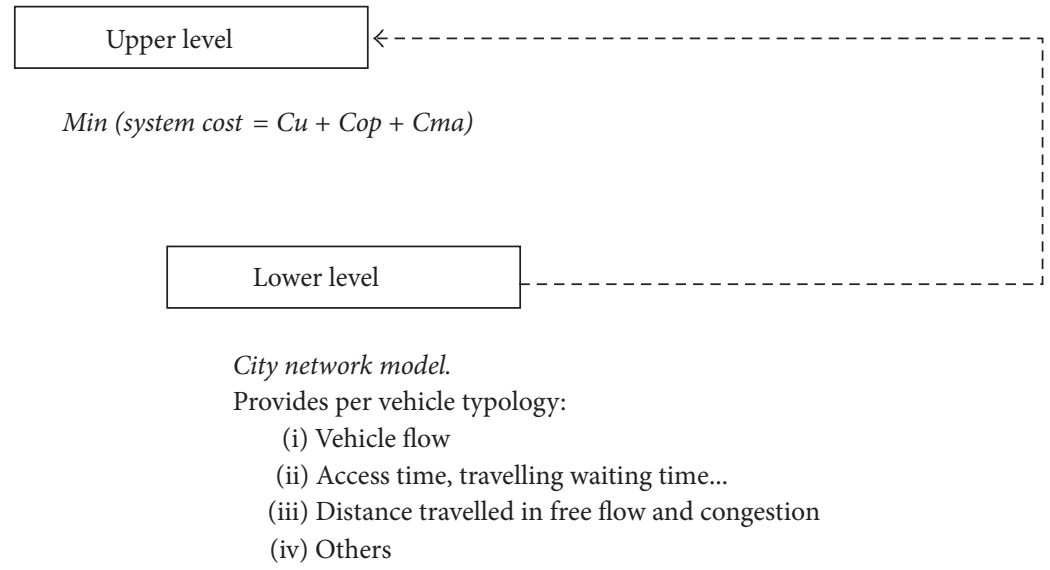

FIGURE 1: Bilevel methodology.

$T_{\text {Wai, } \mathrm{B}}$ is Bus waiting time; $\varphi_{\mathrm{Wai}, \mathrm{B}}$ is bus waiting time worth; $T_{\text {Travel, } \mathrm{B}}$ is bus travel time; $\varphi_{\text {Travel, } \mathrm{B}}$ is bus travel time worth; $T_{\operatorname{Tra}, \mathrm{B}}$ is bus transfer time; $\varphi_{\operatorname{Tra}, \mathrm{B}}$ is bus transfer time worth. lation:

Operating costs are calculated using the following formu-

$$
\begin{aligned}
\mathrm{Cop} & =\mathrm{Cop}_{\mathrm{B}}+\mathrm{Cop}_{\mathrm{Tr}}, \\
\mathrm{Cop}_{\mathrm{B}} & =\mathrm{CR}+\mathrm{CP}+\mathrm{CF}, \\
\mathrm{CR} & =\varphi_{\mathrm{CR}} \cdot \text { Total Km., } \\
\mathrm{CP} & =\varphi_{\mathrm{CP}} \cdot \text { Person hours, } \\
\mathrm{CF} & =\varphi_{\mathrm{CF}} \cdot \mathrm{N}^{\circ} \text { Buses, } \\
\mathrm{Cop}_{\mathrm{Tr}} & =\sum_{i} T_{i} \cdot f_{i} \cdot C_{u}, \\
T & =T_{\text {outward }}+T_{\text {return }}+T_{\text {loading }}+T_{\text {unloading, }},
\end{aligned}
$$

where Cop is total operating costs; $\operatorname{Cop}_{\mathrm{B}}$ is bus operating cost; $\mathrm{Cop}_{\mathrm{Tr}}$ is truck operating cost.

Bus operating costs $\left(\mathrm{Cop}_{\mathrm{B}}\right)$ are made up of three factors: cost proportional to travelled distance (CR), personnel costs $(\mathrm{CP})$, and fixed costs (CF).

Total cost due to the distance travelled by the buses is equal to

$$
\mathrm{CR}=\varphi_{\mathrm{CR}} \cdot \text { Total } \mathrm{Km} \text {., }
$$

where $\varphi_{\mathrm{CR}}$ is unit cost per kilometer covered by bus.

$$
\text { Total Km. }=\sum_{i} L_{i} \cdot f_{i},
$$

where $L_{i}$ is length of route $i$; $f_{i}$ is frequency of route $i$.

Employee costs are calculated considering only the personnel who are really working on the buses:

$$
\mathrm{CP}=\varphi_{\mathrm{CP}} \cdot \text { Person hours, }
$$

where $\varphi_{\mathrm{CP}}$ is the hourly employee cost.

$$
\text { Person hours }=\sum_{i} \frac{t c_{i}}{h_{i}}
$$

where $t c_{i}$ is time of a round trip; $h_{i}$ is headway on route $i$.
Fixed costs are calculated with the following formula that only considers the buses that are really circulating:

$$
\mathrm{CF}=\varphi_{\mathrm{CF}} \cdot \mathrm{N}^{\circ} \text { buses, }
$$

where $\varphi_{\mathrm{CF}}$ is fixed cost per hour of bus.

$$
\mathrm{N}^{\circ} \text { buses }=\sum_{i} \frac{t c_{i}}{h_{i}},
$$

where $t c_{i}$ is time of a round trip; $h_{i}$ is headway on route $i$.

Truck operating cost $\left(\mathrm{Cop}_{\mathrm{Tr}}\right)$ is estimated as

$$
\begin{aligned}
\operatorname{Cop}_{\operatorname{Tr}} & =\sum_{i} T_{i} \cdot f_{i} \cdot C_{u}, \\
T & =T_{\text {outward }}+T_{\text {return }}+T_{\text {loading }}+T_{\text {unloading, }},
\end{aligned}
$$

where $T_{\text {outward }}$ is truck outward time; $T_{\text {return }}$ is truck return time; $T_{\text {loading }}$ is truck loading time; $T_{\text {unloading }}$ is truck unloading time; $C_{u}$ is cost per hour of truck use; $f_{i}$ is truck flow.

The environmental costs (Cma) were calculated for different alternatives considering 5 types of pollutants $(p)$ : NO $x$, NMVOC, $\mathrm{CH} 4, \mathrm{PM} 2.5$, and $\mathrm{CO} 2$, as well as the difference vehicle typologies $(v)$ : petrol cars, diesel cars, buses, heavy lorries (HGV), medium lorries, and lightweight lorries.

$$
\begin{aligned}
& \mathrm{Cma}=\sum_{p} Q_{p} \cdot C_{p} \\
& Q_{p}=\sum_{v}\left(\mathrm{~km} \mathrm{cong}_{v} \cdot \text { Consum.cong }_{v}+\mathrm{km} \text { uncong }_{v}\right. \\
& \text { - Consum.uncong } \left.{ }_{v}\right) \cdot \delta_{v} \cdot \text { Emmisions }_{p, v},
\end{aligned}
$$

where $\mathrm{Cma}$ is total environmental cost. $Q_{p}$ is amount of pollutant $p . C_{p}$ is environmental cost of pollutant $p . \mathrm{km}^{\text {cong }}{ }_{v}$ is $\mathrm{km}$ routed with congested network per vehicle type $v$. $\mathrm{km}$ uncong $\mathrm{g}_{v}$ is $\mathrm{km}$ routed with uncongested network per vehicle type $v$. Consum.cong ${ }_{v}$ is consumption per vehicle type $v$ with congested network. Consum.uncong ${ }_{v}$ is consumption per vehicle type $v$ with uncongested network. $\delta_{v}$ is conversion factor $\mathrm{kg} / \mathrm{litres}$ of fuel per vehicle type $v$. Emmisions ${ }_{p, v}$ is emissions of type $p$ pollutants per vehicle typology $v$. 


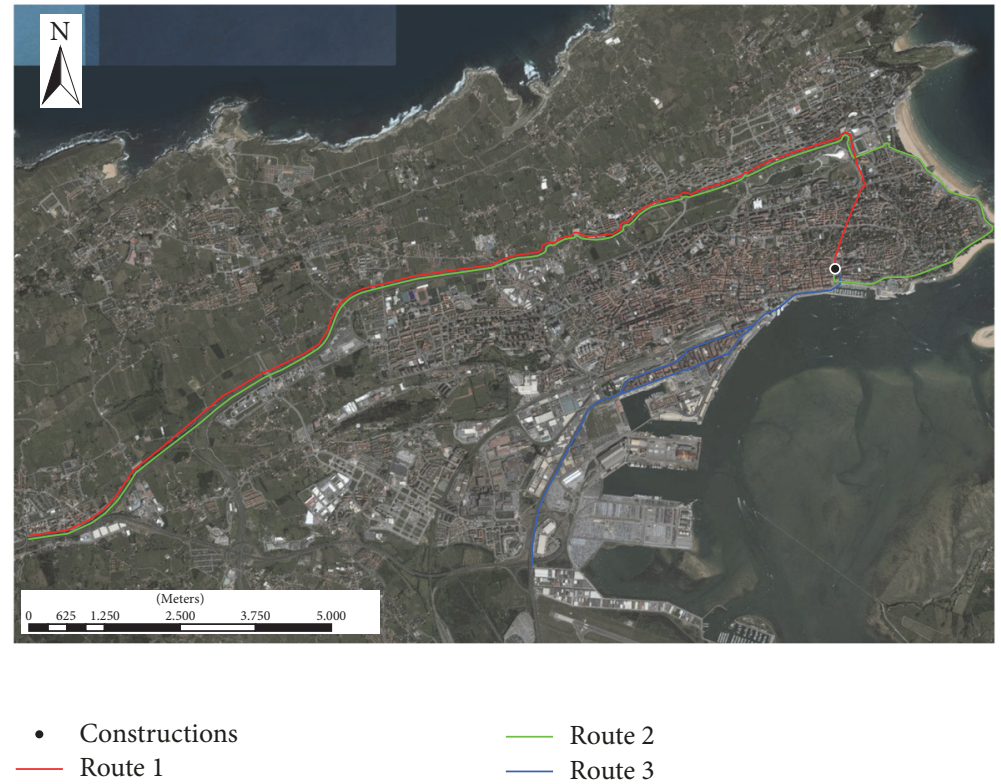

Figure 2: Considered routes.

TABLE 1: Vehicle's consumption rates (litres/Km) and vehicle's emission rates (g of pollutant/Kg of fuel) $[26,27]$.

\begin{tabular}{|c|c|c|c|c|c|c|c|c|}
\hline & \multicolumn{5}{|c|}{ Emissions (g of pollutant/Kg of fuel) } & \multicolumn{2}{|c|}{ Consumption (litres/Km) } & \multirow{2}{*}{$\delta(\mathrm{Kg} /$ litre $)$} \\
\hline & NO $x$ & NMVOC & $\mathrm{CH} 4$ & PM & $\mathrm{CO} 2$ & Congested & Uncongested & \\
\hline Gasoline cars & 10.89 & 13.44 & 1.19 & 0.03 & 3180.00 & 0.08 & 0.06 & 0.680 \\
\hline Diesel cars & 11.12 & 0.61 & 0.07 & 0.80 & 3140.00 & 0.07 & 0.05 & 0.850 \\
\hline Buses & 32.67 & 0.99 & 0.24 & 0.81 & 3140.00 & 0.34 & 0.26 & 0.850 \\
\hline Heavy trucks & & & & & & 0.34 & 0.26 & \\
\hline Medium trucks & 34.84 & 3.06 & 0.38 & 1.34 & 3140.00 & 0.31 & 0.22 & 0.850 \\
\hline Light trucks & & & & & & 0.29 & 0.21 & \\
\hline
\end{tabular}

TABLE 2: Environmental cost of each kind of pollutant (€/ton) [28].

\begin{tabular}{cccccc}
\hline & NO $x$ & NMVOC & $\mathrm{CH} 4$ & $\mathrm{PM}$ & $\mathrm{CO} 2$ \\
\hline$€ /$ ton of pollutant & 3.60 & 800.00 & 775.00 & 114.00 & 29.00 \\
\hline
\end{tabular}

Firstly, fuel consumption per alternative is obtained. Once the emission of pollutants is known, it is calculated per type (Table 1). The emission of pollutants depends on how congested the network is, distance travelled, and vehicle typology [26]. Finally, this is converted into monetary terms (Table 2).

\section{Case Study}

The methodology proposed has been applied to a real case in Santander, a city in northern Spain. Santander is a mediumsized coastal city with approx. 180,000 inhabitants, and approx. $75 \%$ of the city is bordered by water, so it has few access points.

A large construction project in the southeast of the city required delivery of 180 cubic metres of building material during the rush hour. This is the reason for studying the economic, social, and environmental impact caused by an increase in demand for large freight vehicles. The building
TABLE 3: Fleet typologies.

\begin{tabular}{lcc}
\hline Truck size & Cargo capacity (tons) & Maximum speed $(\mathrm{km} / \mathrm{h})$ \\
\hline Light & 9 & 10 \\
Medium & 12 & 15 \\
Heavy & 18 & 20 \\
\hline
\end{tabular}

material would be transported via a fleet of homogenous vehicles, selected from several typologies characterized by their maximum capacity and speed (Table 3 ).

Beginning with Santander network model data [29], three different routes will be considered: the first one (R1) goes through roads with two lanes per direction, with the exception of an 800-metre tunnel at the end of it; the second route (R2) differs only from R1 in that instead of going through the tunnel, it borders the city using coastal 1-lane per direction roads; and the third route (R3) travels through some streets that, though they have two or three lanes per direction, are also the most congested ones in the city. See Figure 2.

Each route has two legs, which contribute to its total travel time and length: an urban one (inside Santander) and an external one (from the quarry to the outskirts of the city). 


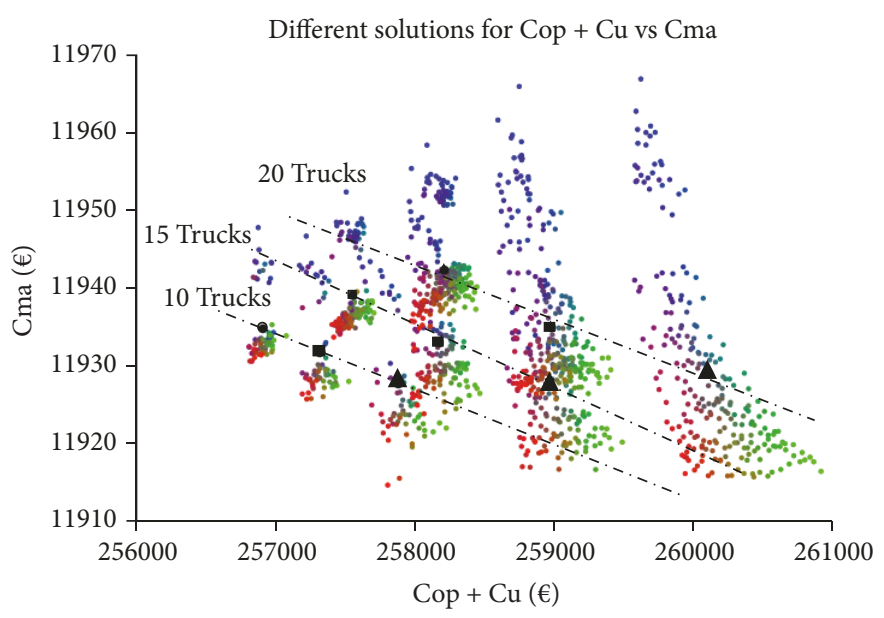

- Mass center for light trucks cases

- Mass center for medium trucks cases

A Mass center for heavy trucks cases

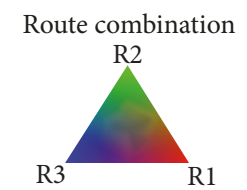

Figure 3: Different solutions for Cop $+\mathrm{Cu}$ versus $\mathrm{Cma}$.

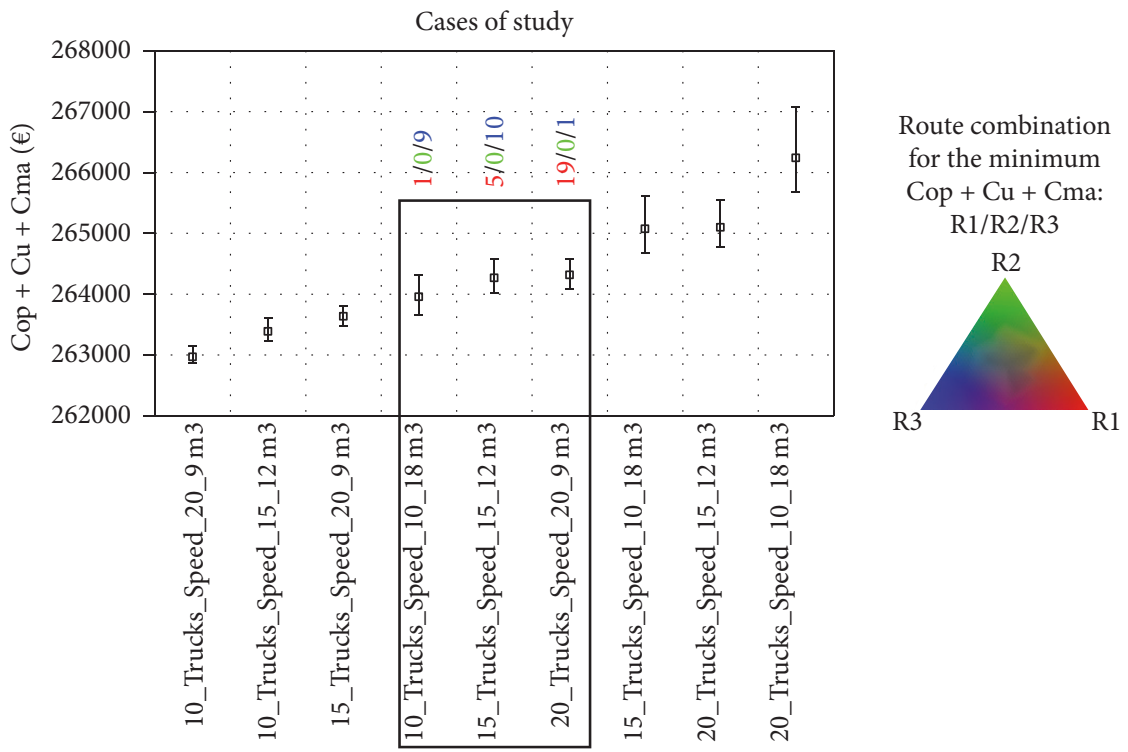

Figure 4: Total cost value for the cases of study.

First of all, model behaviour was verified studying all possible means of moving the vehicle fleet from the quarry to building site via 3 predefined routes. The vehicle fleet may be of different typologies as already mentioned (Table 3); furthermore, 3 different fleet sizes were considered, that is, 10,15 , and 20 vehicles. Application of the model resulted in the obtainment of operation, user, and environmental costs per scenario in monetary terms (Figure 3 ). The difference between each scenario is the number of vehicles travelling along each route.

With this figure we can see that the model behaves as expected; that is, for the same size fleet, the combined user and operator costs increase the heavier and slower the lorry is, whereas environmental costs increase when the fleet consists of smaller lorries. Nevertheless, as might be expected costs increased with the size of the fleet for the same lorry typology. Moreover, as can be seen per scenario, if the majority of the fleet takes route 3 (R3) (blue dots at the top of the graph), environmental costs are higher than if routes 1 and/or 2 are taken; whereas should the majority of the fleet use route 2 (R2), the combined operation and user costs are higher. In terms of both combined user and operator costs and environmental costs, the best solutions correspond to those scenarios where most of the fleet uses route 1 (red dots).

Figure 4 shows the total costs for the different fleet size and typology combinations, indicating the total average 

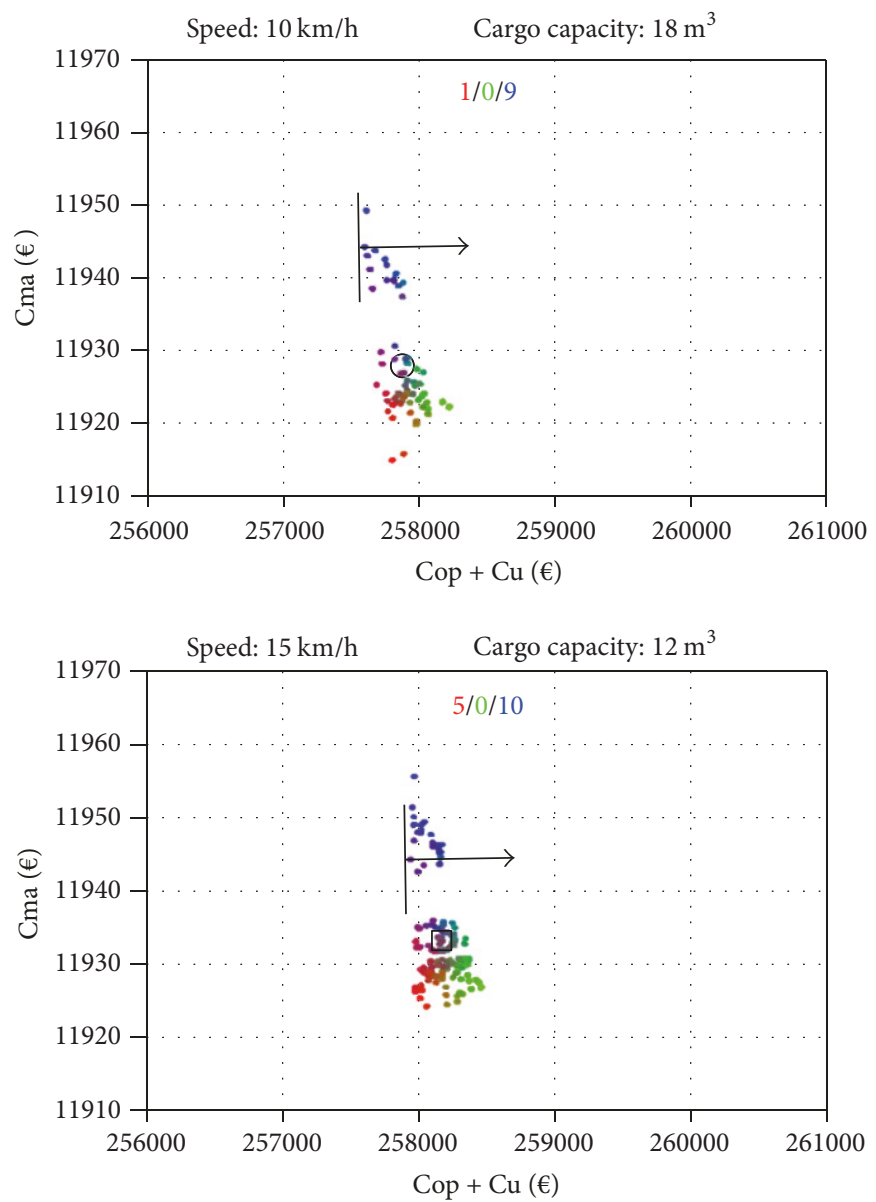

$\alpha$ value for the same weight of $(\mathrm{Cop}+\mathrm{Cu}) \& \mathrm{Cma}$
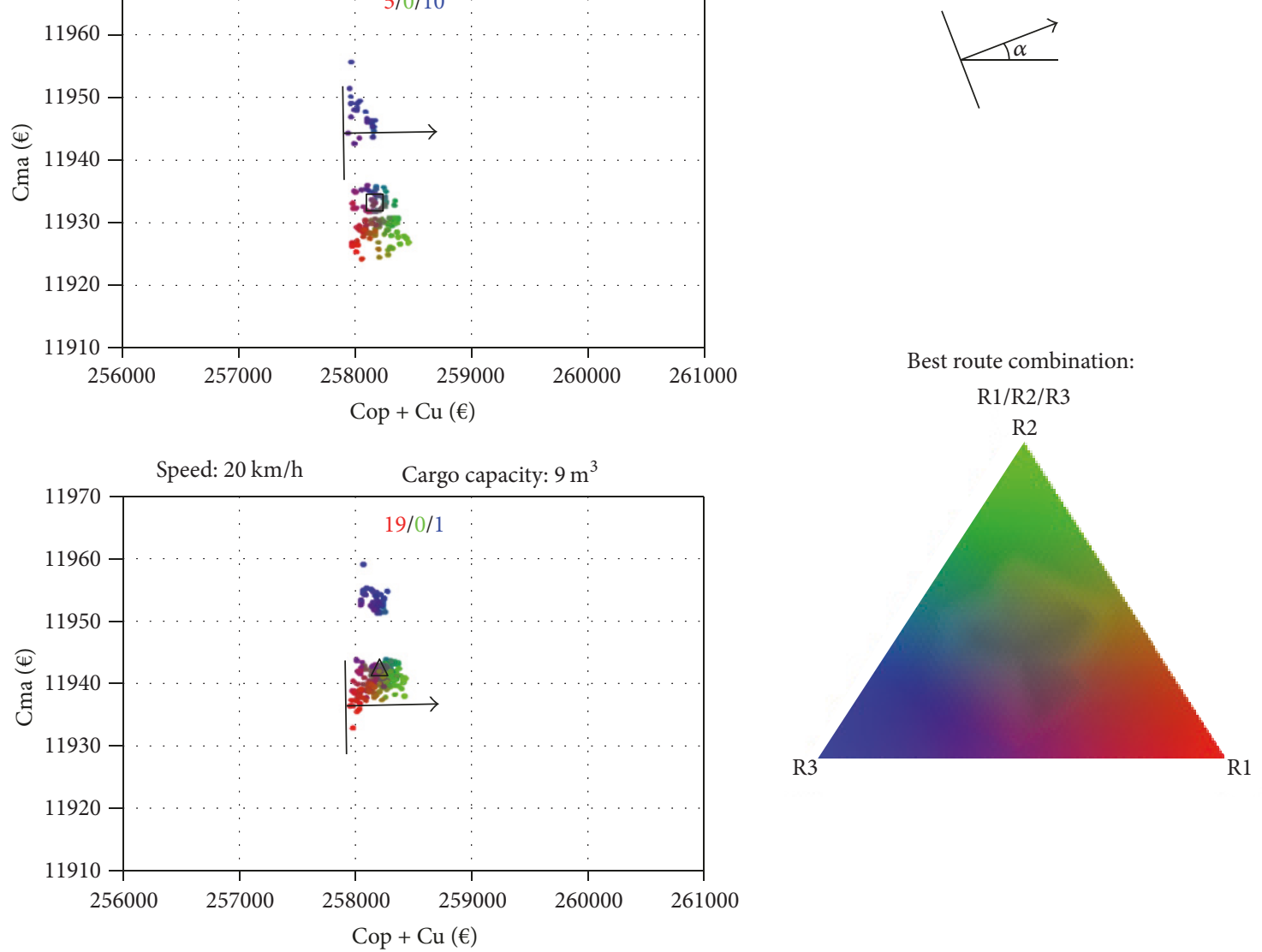

Mass center for 10 trucks' case

$\square$ Mass center for 15trucks' case

$\triangle$ Mass center for 20 trucks' case

Figure 5: Possible ways to transport the load.

cost per combination and likewise the total maximum and minimum cost.

Getting back to our study case where the building site required delivery of 180 cubic metres during the rush hour, per vehicle typology, the solutions with lower costs are shown in Figure 4. Figure 5 shows these 3 possibilities in greater detail together with the number of vehicles per route for the average cost.

If the planner needs the solution that minimizes environmental costs, he should move in a line parallel to the $x$-axis $\left(\alpha=0^{\circ}\right)$, starting at $\mathrm{Cma}=0$, and choose the first solution touched by it, which corresponds to sending 10 heavy trucks 


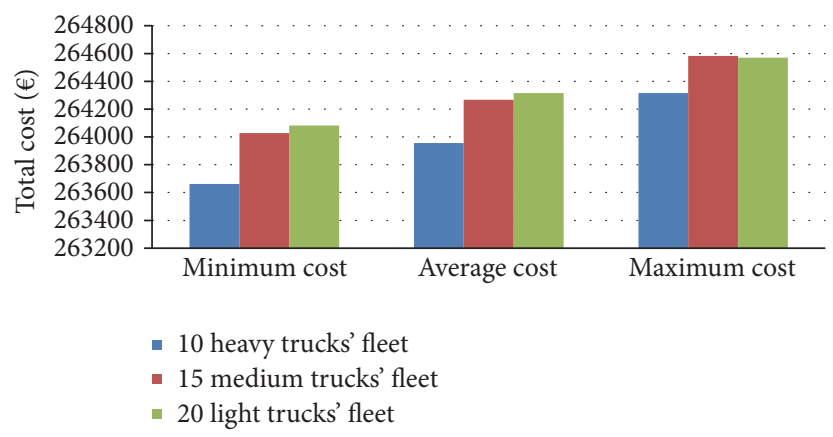

Figure 6: Minimum, average, and maximum cost for the three vehicle typologies.

through R1. If our objective were to minimize Cop $+\mathrm{Cu}$, the process would be similar, but using a line parallel to the $y$-axis instead $\left(\alpha=90^{\circ}\right)$. In this case, we should also use 10 heavy trucks, with ten of them going through R3. If only medium or light trucks were available, to minimize Cop $+\mathrm{Cu}$ most of the fleet should travel through R3 or R1, respectively. Other intermediate Pareto solutions, with different emphases in the environmental or in the user and operator costs, can be found using values of $\alpha$ between $0^{\circ}$ and $90^{\circ}$.

Figure 5 shows which alpha value to use if $\mathrm{Cma}$ and $(\mathrm{Cop}+\mathrm{Cu})$ had the same importance. Below, the following is shown and represented (Figure 6): the 3 vehicle typologies (heavy, medium, and light), the minimum, average, and maximum costs necessary to move the building material from the quarry to the site, and likewise the number of lorries which would use each of the 3 routes available.

(i) 10 heavy trucks' fleet:

(a) Minimum cost: 263.661,08 $€(\mathrm{R} 1 / \mathrm{R} 2 / \mathrm{R} 3: 1 / 0 / 9)$

(b) Average cost: $263.956,73 €$

(c) Maximum cost: 264.325,87€ (R1/R2/R3: 0/10/0)

(d) Difference between max. and min. costs: 664,79 $€$

(ii) 15 medium trucks' fleet:

(a) Minimum cost: 264.027,50 € (R1/R2/R3: 5/0/10)

(b) Average cost: $264.267,95 €$

(c) Maximum cost: 264.582,49€ (R1/R2/R3: 0/15/0)

(d) Difference between max. and min. costs: 554,91 $€$

(iii) 20 light trucks' fleet:

(a) Minimum cost: 264.081,94 € (R1/R2/R3: 19/0/1)

(b) Average cost: 264.315,18 €

(c) Maximum cost: 264.570,07 € (R1/R2/R3: 0/19/1)

(iv) Difference between max. and min. costs: $488,12 €$

Regarding total costs, it can be seen that using a fleet of 10 heavy trucks results in significantly lower total costs (minimum as well as average or maximum). There is little difference between using a fleet of 15 medium trucks or/and
20 light trucks, the former being cheaper than the latter in terms of minimum and average costs, while it is slightly more expensive when considering maximum costs. In conclusion, if a fleet of 10 heavy trucks is available, it is the option less costly from the environmental, economic, and social points of view.

\section{Conclusions}

This paper presents a model to optimize management and planning of special freight vehicles coming from outside the city to a specific point in the centre. The proposed model minimizes freight vehicle impact for those occasions when there is movement of large quantities of goods. The strength of the model is that it is based on bilevel mathematical programming, making a more realistic reflection of the practical problem possible by allowing variables that represent aspects of the city network to be nested within the problem of cost minimization. Furthermore, the model minimizes freight vehicle impact for those occasions when there is movement of large quantities of goods.

The model was applied to Santander (Spain) for the case where a large quantity of building materials had to be delivered to a specific point in the city characterized by a high mobility rate of both private and public transport, due to a large building site. In addition to selecting their typology, vehicles may also be assigned to different routes to minimize total system costs.

The model provides solutions for different vehicle typologies. The most economical solution considering the total system costs, that is, user, operation, and environmental costs, would be to use $10 \mathrm{HGVs}, 1$ vehicle via route R1 and the other 9 via route R3. However, if the purpose is to find the best solution from an environmental viewpoint, then these $10 \mathrm{HGVs}$ should use route R1. Nevertheless, should only lightweight vehicles be available, then the best environmental solution would be to assign 15 vehicles to route $\mathrm{R} 1$ and 5 to route R3; and regarding total costs the best solution would be 10 vehicles via $R 1$, 9 via $R 2$, and 1 via $R 1$.

In conclusion, we have learnt from the model proposed that large vehicle management and planning reduce impact on cities, from a social, economic, and/or environmental viewpoint. Selection of both vehicle typology and routes to be used and followed is important in the reduction of the costs which the movement of said vehicles causes. 


\section{Conflicts of Interest}

The authors declare that there are no conflicts of interest regarding the publication of this paper.

\section{References}

[1] J. Holguín-Veras, K. Ozbay, A. Kornhauser et al., "Overall impacts of off-hour delivery programs in New York city metropolitan area," Journal of The Transportation Research Record, vol. 2238, pp. 68-76, 2011.

[2] M. Browne, J. Allen, T. Nemoto, D. Patier, and J. Visser, "Reducing social and environmental impacts of urban freight transport: a review of some major cities," Procedia - Social and Behavioral Sciences, vol. 39, pp. 19-33, 2012.

[3] J. Visser, T. Nemoto, and M. Browne, "Home delivery and the impacts on urban freight transport: a review," Procedia - Social and Behavioral Sciences, vol. 125, pp. 15-27, 2014.

[4] H. J. Quak and M. De Koster, "Urban distribution: the impacts of different governmental time-window schemes," ERIM Report Series Reference ERS-2006-053-LIS, 2006.

[5] E. a. d. Santander, "Ordenanza de circulación del excmo. ayuntamiento de Santander," Boletin Oficial de Cantabria, vol. 103, 2016.

[6] R. Capitale, Ordinanza Sindicale n.88 del 27 ottobre, 2016.

[7] J. P. Romero, J. Benavente, J. L. Moura, A. Ibeas, and B. Alonso, "An environmental approach to optimize urban freight transport systems," Advances in Intelligent Systems and Computing, vol. 262, pp. 127-136, 2014.

[8] T. Schoenherr, "Logistics and supply chain management applications within a global context: an overview," Journal of Business Logistics, vol. 30, no. 2, pp. 1-25, 2009.

[9] G. Reiner and M. Trcka, "Customized supply chain design: problems and alternatives for a production company in the food industry. a simulation based analysis," International Journal of Production Economics, vol. 89, no. 2, pp. 217-229, 2004.

[10] J. Guo, X. Wang, S. Fan, and M. Gen, "Forward and reverse logistics network and route planning under the environment of low-carbon emissions: A case study of Shanghai fresh food E-commerce enterprises," Computers \& Industrial Engineering, vol. 106, pp. 351-360, 2017.

[11] L. Wu, X. Yue, A. Jin, and D. C. Yen, "Smart supply chain management: a review and implications for future research," International Journal of Logistics Management, vol. 27, no. 2, pp. 395-417, 2016.

[12] C. Öberg and G. Graham, "How smart cities will change supply chain management: a technical viewpoint," Production Planning and Control, vol. 27, no. 6, pp. 529-538, 2016.

[13] J. F. Bard, "Optimality conditions for the bilevel programming problem," Naval Research Logistics Quarterly, vol. 31, no. 1, pp. 13-26, 1984.

[14] Á. Ibeas, L. Dell'Olio, B. Alonso, and O. Sainz, "Optimizing bus stop spacing in urban areas," Transportation Research Part E: Logistics and Transportation Review, vol. 46, no. 3, pp. 446-458, 2010.

[15] J. S. Chang and R. L. Mackett, "A bi-level model of the relationship between transport and residential location," Transportation Research Part B: Methodological, vol. 40, no. 2, pp. 123-146, 2006.

[16] J. L. Moura, A. Ibeas, and L. dell'Olio, "Optimization-simulation model for planning supply transport to large infrastructure public works located in congested urban areas," Networks and Spatial Economics, vol. 10, no. 4, pp. 487-507, 2010.

[17] H. Sun, Z. Gao, and J. Wu, "A bi-level programming model and solution algorithm for the location of logistics distribution centers," Applied Mathematical Modelling, vol. 32, no. 4, pp. 610616, 2008.

[18] EEA, Emissions of Air Pollutants from Transport, European Environment agency, 2013.

[19] M. Adams, S. Cryan, A. Mourelatou, and K. Nytorv, Air emission inventory data in europe: new perspectives, 2009.

[20] P. Kumar, L. Morawska, C. Martani et al., "The rise of lowcost sensing for managing air pollution in cities," Environment International, vol. 75, pp. 199-205, 2015.

[21] E. Demir, T. Bektaş, and G. Laporte, "A review of recent research on green road freight transportation," European Journal of Operational Research, vol. 237, no. 3, pp. 775-793, 2014.

[22] J. S. Wang, T. L. Chan, Z. Ning, C. W. Leung, C. S. Cheung, and W. T. Hung, "Roadside measurement and prediction of CO and PM2.5 dispersion from on-road vehicles in Hong Kong," Transportation Research Part D: Transport and Environment, vol. 11, no. 4, pp. 242-249, 2006.

[23] S. Behrends, M. Lindholm, and J. Woxenius, "The impact of urban freight transport: a definition of sustainability from an actor's perspective," Transportation Planning and Technology, vol. 31, no. 6, pp. 693-713, 2008.

[24] S. Yan, W. Lai, and M. Chen, "Production scheduling and truck dispatching of ready mixed concrete," Transportation Research Part E: Logistics and Transportation Review, vol. 44, no. 1, pp. 164-179, 2008.

[25] Q. He, L. Hu, and H. Qian, "Low-carbon sales logistics network planning method based on multi-objective planning," Systems Engineering, vol. 7, pp. 37-43, 2013.

[26] EMEP/EEA, "EMEP/EEA air pollutant emission inventory guidebook 2009," Technical guidance to prepare national emission inventories, 2009.

[27] IDAE, "Guía de vehículos turismo de venta en España, con indicación de consumos y emisiones de $\mathrm{CO}_{2}, 2013$ ".

[28] H. van Essen et al., External Costs of Transport in Europe. Update Study for 2008, 2011.

[29] J. P. Romero, A. Ibeas, J. L. Moura, J. Benavente, and B. Alonso, "A Simulation-optimization approach to design efficient systems of bike-sharing," Procedia - Social and Behavioral Sciences, vol. 54, pp. 646-655, 2012. 


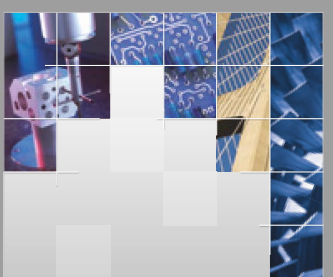

\section{Enfincering}
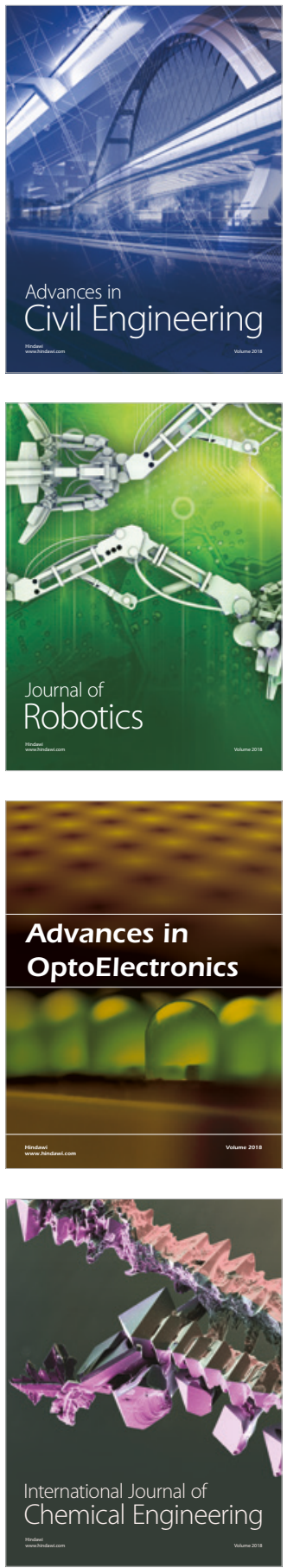

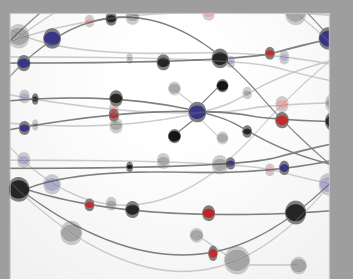

\section{Rotating \\ Machinery}

The Scientific World Journal

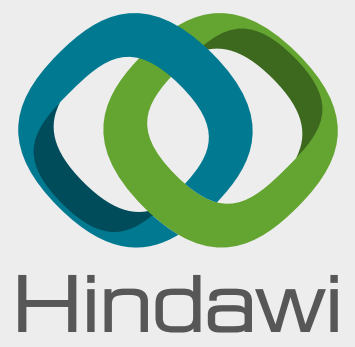

Submit your manuscripts at

www.hindawi.com
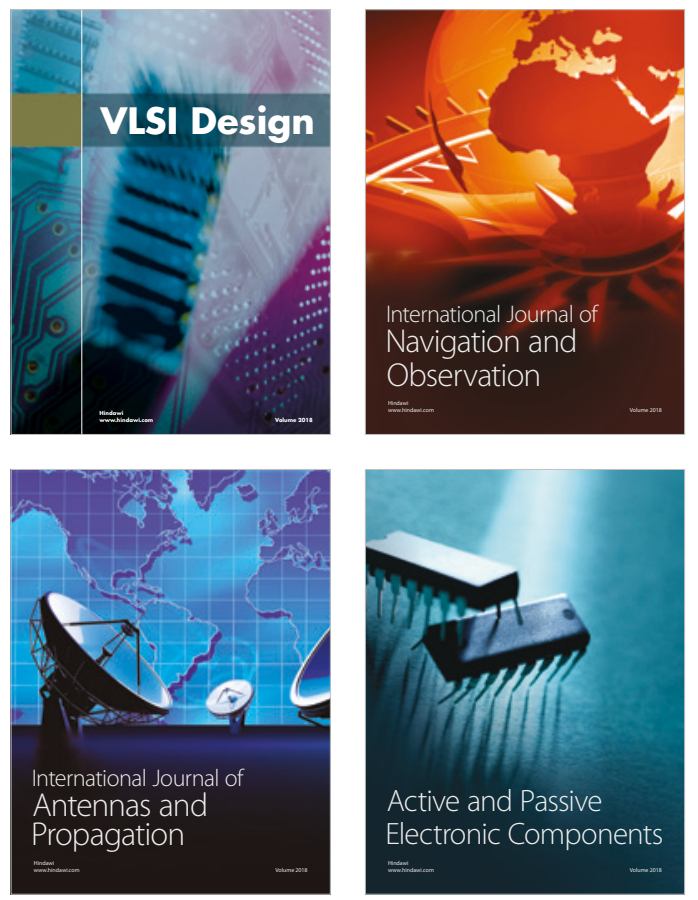
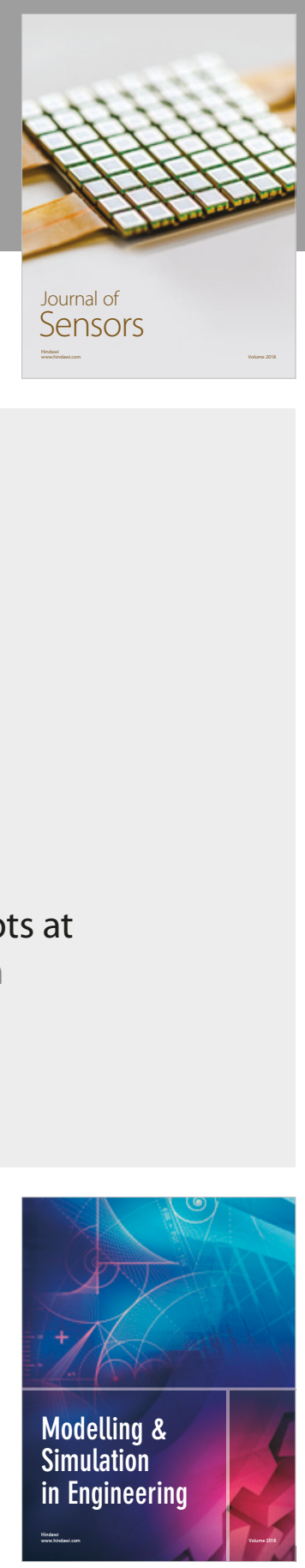

\section{Advances \\ Multimedia}
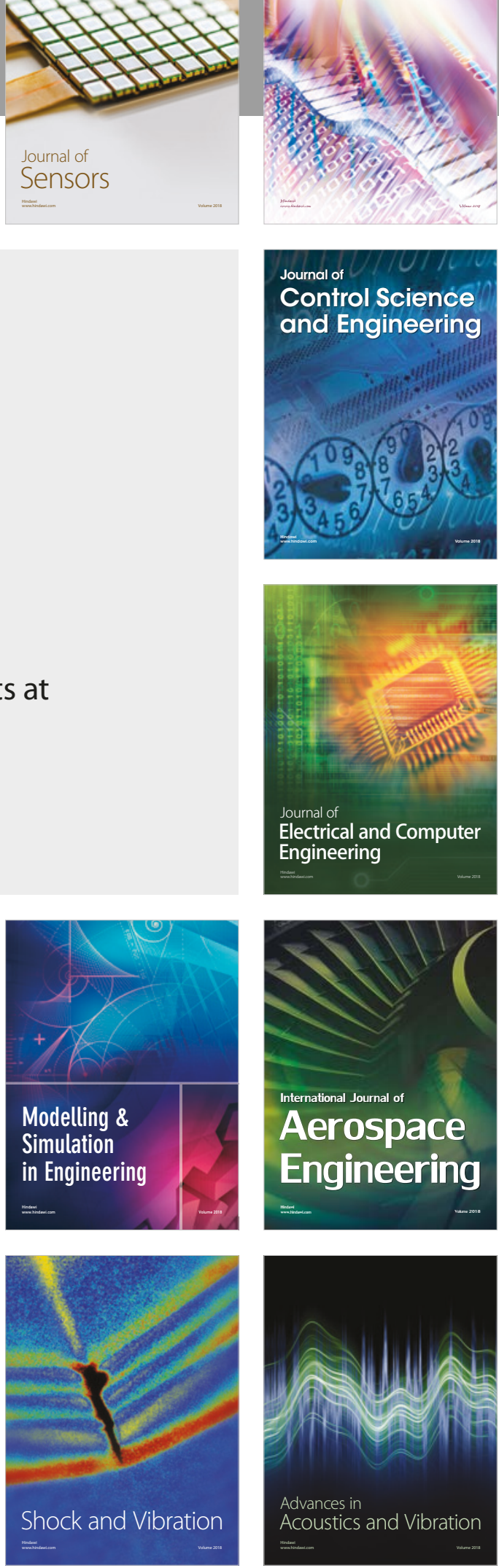